\title{
Necessity of secondary Syme amputation of the foot after severely destroyed hindfoot injury due to suicidal jump from height in a psychiatric patient: Case presentation and brief review of literature
}

\author{
Ingo Schmidt ${ }^{1 *}$, Andrea Schmieder ${ }^{2}$ \\ ${ }^{1}$ SRH Poliklinik Gera GmbH, Straße des Friedens 122, 07548 Gera, Germany \\ ${ }^{2}$ Orthopädische Praxis (MVZ) Klinikum Burgenlandkreis GmbH, Humboldtstr, Naumburg, Germany
}

\begin{abstract}
Abbreviations: 3D CT : three-dimensional computed tomography; CREF: closed reduction and external fixation; DPNFCSAF: distally pedicled neurofasciocutaneous sural artery flap; O(C)RIF: open (closed) reduction and internal fixation.
\end{abstract}

\section{Case presentation}

A 44-year-old obese female (body mass index $37.2 \mathrm{~kg} / \mathrm{m}^{2}$ ) presented with open severely destroyed injuries of her both hindfoots after a suicidal jump from approximately $4 \mathrm{~m}$ height out of her private balcony. There was a longstanding history of a psychiatric disorder (schizophrenia) treated by psychopharmaca. The left foot showed an open Gustilo-Anderson II hindfoot injury at the lateral aspect of calcaneus, and three-dimensional computed tomography (3D CT) revealed a highly comminuted hindfoot fracture-dislocation injury involving the calcaneus, the subtalar joint, and the Chopart joint (Figure 1A). The right foot showed an open Gustilo-Anderson IIIB hindfoot injury at the medial-plantar aspect of calcaneus, and 3D CT revealed a highly comminuted calacaneus fracture (Figure 1B).

Both injuries were initially treated by closed reduction and external fixation (CREF) accompanied with percutaneous pinning, negative-pressure vacuum assisted closure (VAC) therapy, and intravenous application of antibiotics (cefuroxime). Against our strict recommendations not to load her both legs, the patient mobilized herself with full-weight bearing and went away several times from our hospital and so nearly all pins of external and internal fixations were broken. As a consequence, the overall pins for external and internal fixation of both foots had to be removed 4 weeks after primary surgery, resulting in severe posttraumatic flat foot on both sites based on pronounced bony destruction and fragment dislocation and diastases of the calcaneus bones accompanied with re-dislocation in her left Chopart joint (Figures 2A and 3A). After intermittent negativepressure VAC therapy, a secondary wound closure of her left open II injury could be achieved without additional soft tissue coverage 3 weeks after injury. For closure of her right open IIIB injury, wound coverage with the use of a distally pedicled neurofasciocutaneous sural artery flap (DPNFCSAF) was performed 1 week after removal of the pins. For this purpose, the pedicle of the flap was primarily covered by a synthetic skin substitute (Epigard) at its $160^{\circ}$ pivot point extending up distally to the flap, and secondarily covered by split-thickness skin grafts 1 week later that was associated with an uneventful wound healing (i.e. flap survival) (Figures 2B-C).
At the left foot, the further course after secondary wound closure of her open II injury without the need of coverage was complicated by development of severe osteomylitis of the hindfoot involving the distal tibia metaphysis presented with marked swelling of the overall foot and an infectious fistula at the lateral aspect of calcaneus (Staphylococcus aureus) (Figures 3A-B). Hence, the Syme amputation was detected and performed by us that was associated with an uneventful course (Figures 3C-F). Noted, that the pulse of posterior tibial artery was palpable before amputation. Hindfoot osteomyelitis involving the distal tibia metaphysis was confirmed by histological examination. Six months after amputation, the patient could be mobilized with full-weight bearing of her both legs with the use of an individually customized length balancing prosthetic foot device for the Syme stump (Moritz Klinik Bad Klosterlausnitz / Germany, Chief at this time: Dr. med. Uwe Neumann / Senior Chief: PD Dr. med. habil. Lutz Brückner) (Figure 3G). At this time, the Syme amputation of her right painful posttraumatic flat foot was wished by the patient as well, but we have not positioned ourselves for the time being in addition. After that, the patient did not return in our hospital again.

Falls or jumps from height are high-energy injuries associated with amount of polytraumatized patients up to $65 \%$ (Figures $4 \mathrm{~A}-\mathrm{B}$ ) and a lethality up to $12.5 \%[1,2]$. Jumps from heights are the most common method for suicide in the western population with a relative portion ranging from $44.1 \%$ to $45.8 \%$, followed by hanging with a relative portion of $40.3 \%$, and in $97.7 \%$ of cases the suicides were committed outside a hospital $[2,3]$. In $45.5 \%$ of cases with suicidal jumps, the psychiatric patients (schizophrenics, endogenous depressives) were formerly treated stationary in a hospital, and $12.5 \%$ of the psychiatric patients were addicted to opiates and hallucinogenics $[2,3]$. Furthermore, it is

Correspondence to: Ingo Schmidt, SRH Poliklinik Gera GmbH, Straße des Friedens 122, 07548 Gera, Germany, Tel: 00491789503035; E-mail: schmidtingo62@ googlemail.com

Key words: Psychiatric disorder; Suicidal jump; Fracture-dislocation injury hindfoot; Highly comminuted calacaneus fracture; Soft tissue defect; Coverage; Distally pedicled sural artery flap; Posttraumatic flat foot; Osteomyelitis; Syme amputation; Recovery; Compliance of patients

Received: September 01, 2017; Accepted: September 15, 2017; Published: September 20, 2017 
Schmidt I (2017) Necessity of secondary Syme amputation of the foot after severely destroyed hindfoot injury due to suicidal jump from height in a psychiatric patient: Case presentation and brief review of literature

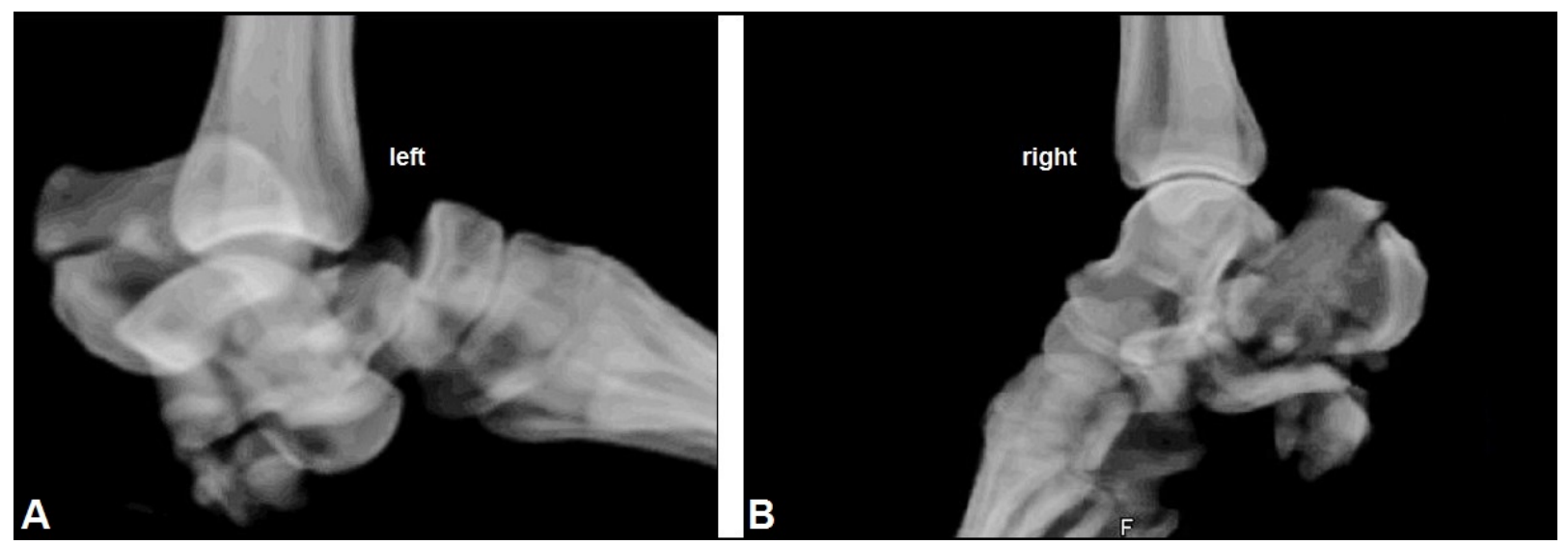

Figure 1. (Case Presentation, initial findings): (A) 3D CT of the left foot showing highly comminuted calcaneus fracture combined with complete dislocations of subtalar and Chopart joints. (B) 3D CT of the right foot showing highly comminuted calcaneus fracture.

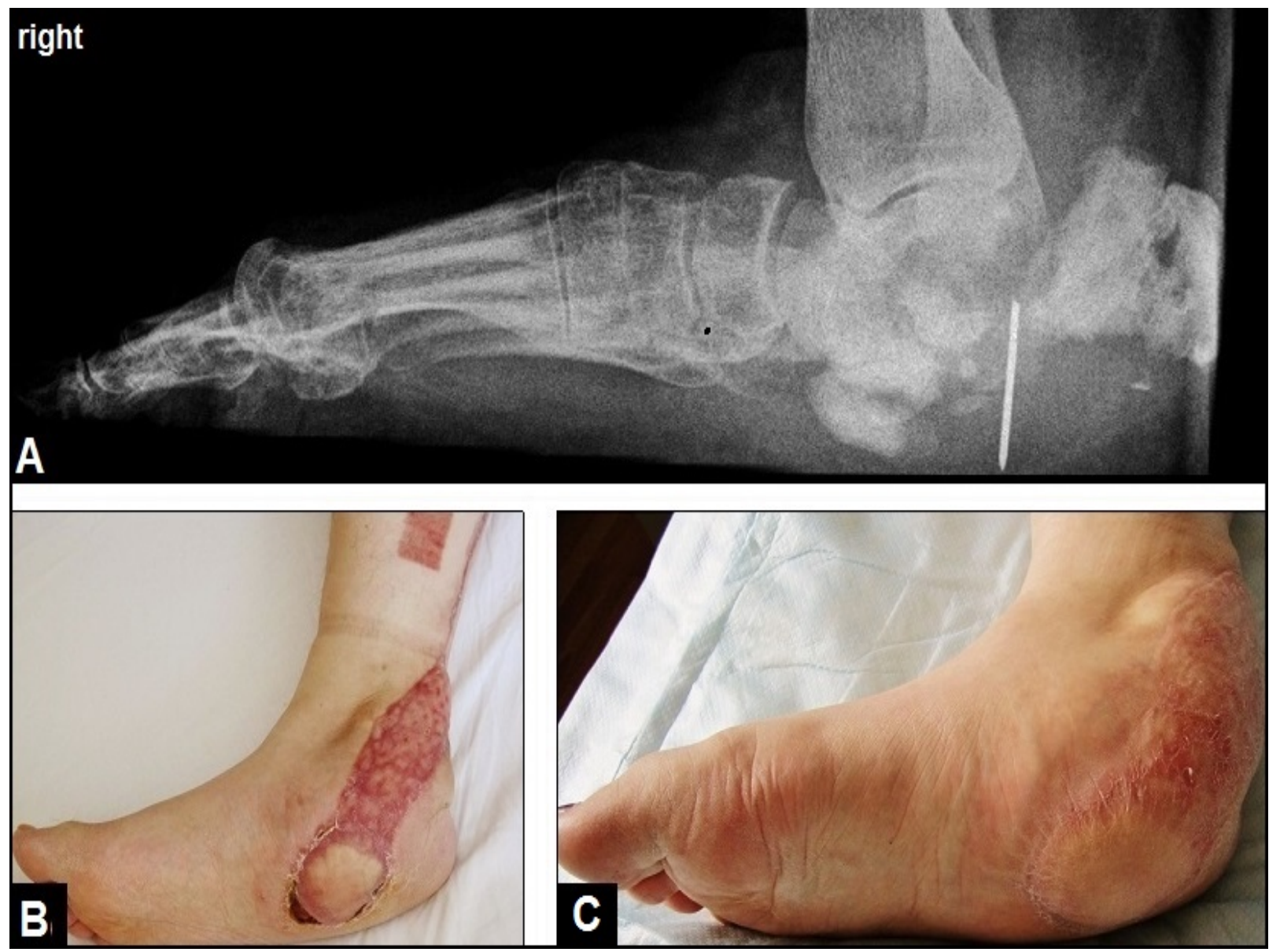

Figure 2. (Case Presentation, course right foot): (A) Lateral radiograph demonstrating severe posttraumatic flat foot based on pronounced bony destruction and fragment diastasis of the calcaneus, note that there is still 1 broken pin in vivo which was definitively removed at time of coverage. (B) Clinical photograph showing wound coverage of IIIB injury at the medialplantar aspect of calcaneus with the DPNFCSAF, the pedicle at its $160^{\circ}$ pivot point extending up distally to the flap was secondarily covered by split-thickness skin grafts. (C) Clinical photograph 6 months after injury showing uneventful wound healing.

noted that the numerical ratio between natural deaths due to a cancer and the suicides of cancer patients is about 1:1,000 [3].

Regarding to the injury pattern of the lower extremities and head after falls or jumps from height there are some differences, the amount after accidental falls is reported to be $23 \%$ and it raises up significantly to $65 \%$ after suicidal jumps for the lower extremities, whereas head injuries significantly decrease from $54 \%$ after accidental falls to $26 \%$ after suicidal jumps [4]. In $57.3 \%$ of cases with injuries of the lower extremities after suicidal jumps, the distal lower leg, ankle and foot are concerned [2]. Falls from height higher than $3 \mathrm{~m}$ and attempted suicide are associated with a higher incidence of injuries of the ankle and foot than traffic accidents, and the amount of high-energy fracture- 


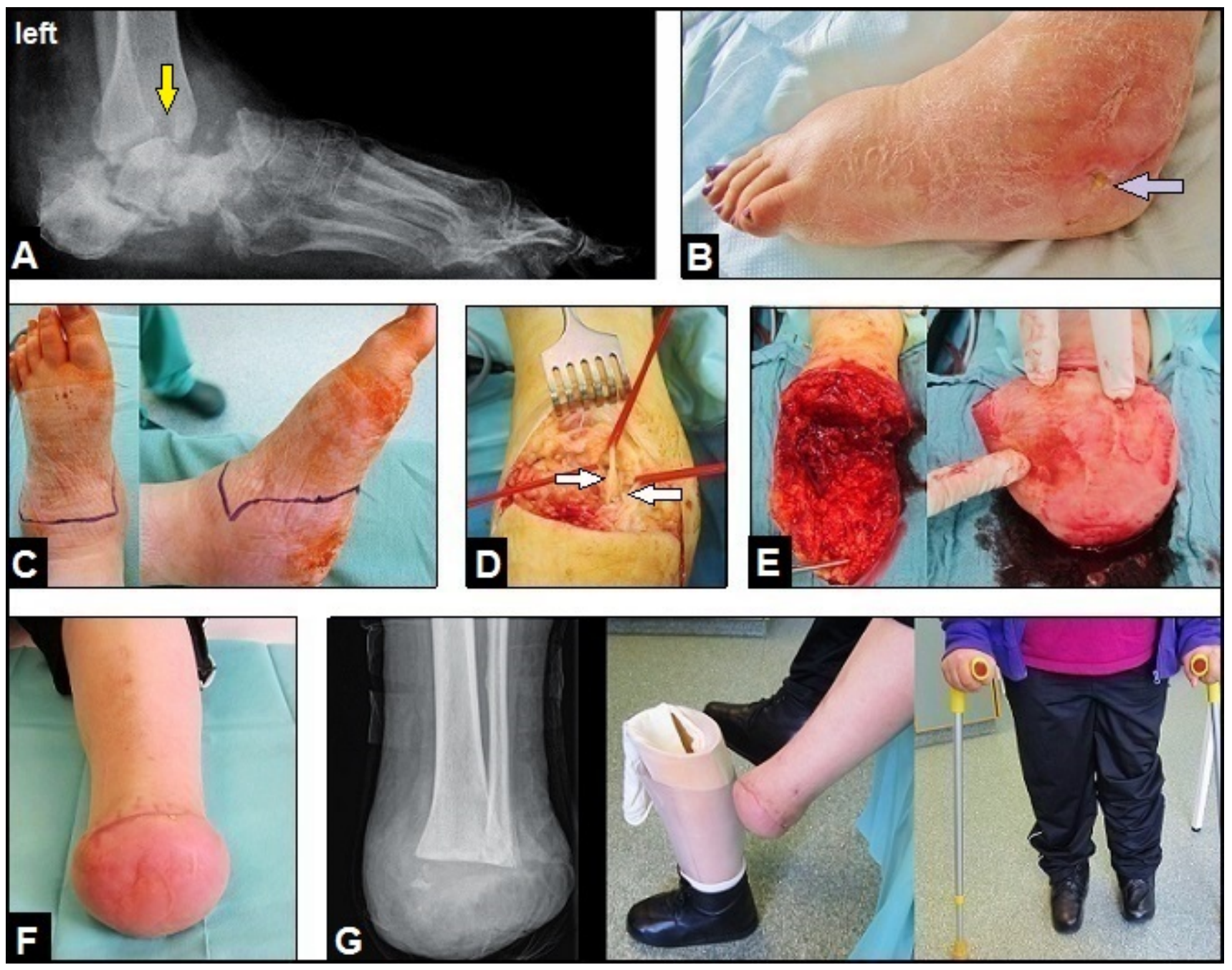

Figure 3. (Case Presentation, course left foot): (A) Lateral radiograph demonstrating severe posttraumatic flat foot based on pronounced bony destruction and fragment dislocation of the calcaneus, re-dislocation in Chopart joint, and the infectious osteolysis in the distal tibia metapysis (arrow) (B) Clinical photograph showing marked swelling of the overall foot and the infectious fistula at the lateral aspect of calcaneus (arrow). (C) Clinical photograph showing planning of surgical incisions for Syme amputation. (D) Intraoperative clinical photograph showing the dorsal incision of Syme amputation, both peroneal nerves are dissected (arrows). (E) Intraoperative clinical photographs showing the dissected end-bearing plantar heel flap after disarticulation with sufficient arterial blood supply in the absence of venous congestion. (F) Clinical photograph showing the uneventful healing of the bulky Syme stump. (G) Posteroanterior radiograph and clinical photographs 6 months after amputation demonstrating full-weight bearing mobilization of the patient with the use of the left individually customized length balancing prosthetic foot device (i.e. Syme prosthesis) for the end-bearing stump with its broad-based bony support on the distal tibia/fibula metaphysis.

dislocation injuries involving the Chopart joint is with a relative portion of 55\% much more higher than pure Chopart joint dislocation with a relative portion of $25 \%$ and fracture-dislocation injuries involving both the Chopart and Lisfranc joints with a relative portion of $20 \%[5,6]$. It is important to know that high-energy injuries of the ankle and foot are generally associated with severe closed or open soft tissue injuries [5-8]. Highly comminuted injuries of the upper extremity in patients with high-energy traumata without concomitant injuries of the ankle and foot were observed $33.3 \%$ of cases and it raises up to $43.5 \%$ of cases with concomitant injuries of the ankle and foot, and it has been also observed in $77.1 \%$ of cases after suicidal jumps mostly involving the distal forearm and hand (Figure 5A) with a relative portion of $40.5 \%$ followed by injuries of the elbow (Figures $6 \mathrm{~A}$ and $7 \mathrm{~A}$ ) with a relative portion of $29,7 \%[2,5]$. Primary surgical amputation of severely destroyed injuries of the upper and lower extremities are absolutely indicated in critically ill polytraumatized patients (i.e. life before limb) when the injured extremity showing complete ischemia such as in case of a subtotal amputation $[6,9,10]$.
Highly comminuted fractures or fracture-dislocation injuries with concomitant severe closed or open soft tissue injuries especially at the critical distal third of lower leg, ankle and hindfoot where the bradytrophe bony tissue is not surrounded by well vascularized defending muscles (Figure 8A) represent a challenging therapeutic problem [11]. In general, surgical treatment typically involves the three-stage management both at the upper and lower extremities without any differences that is based on the fundamental knowledge by Gustilo and Anderson in the late 70th's to prevent bony infection [7,1215]. The first stage includes CREF, first applied in 1843 by Malgaigne and later modified in 1902 by Lambotte, to restore length of bone and alignment of its axis, and joint congruency by ligamentotaxis with or without additional percutaneous pinning (Figures 4A, 5B, 6A, 7B and 8B) [16-19]. If a compartment syndrome exists, surgical fasciotomy must be performed [20]. If an open soft tissue injury is present, CREF must be accompanied by wound debridement and negativepressure VAC therapy. Negative-pressure VAC therapy before soft tissue coverage provides a sterile and controlled environment that 
Schmidt I (2017) Necessity of secondary Syme amputation of the foot after severely destroyed hindfoot injury due to suicidal jump from height in a psychiatric patient: Case presentation and brief review of literature
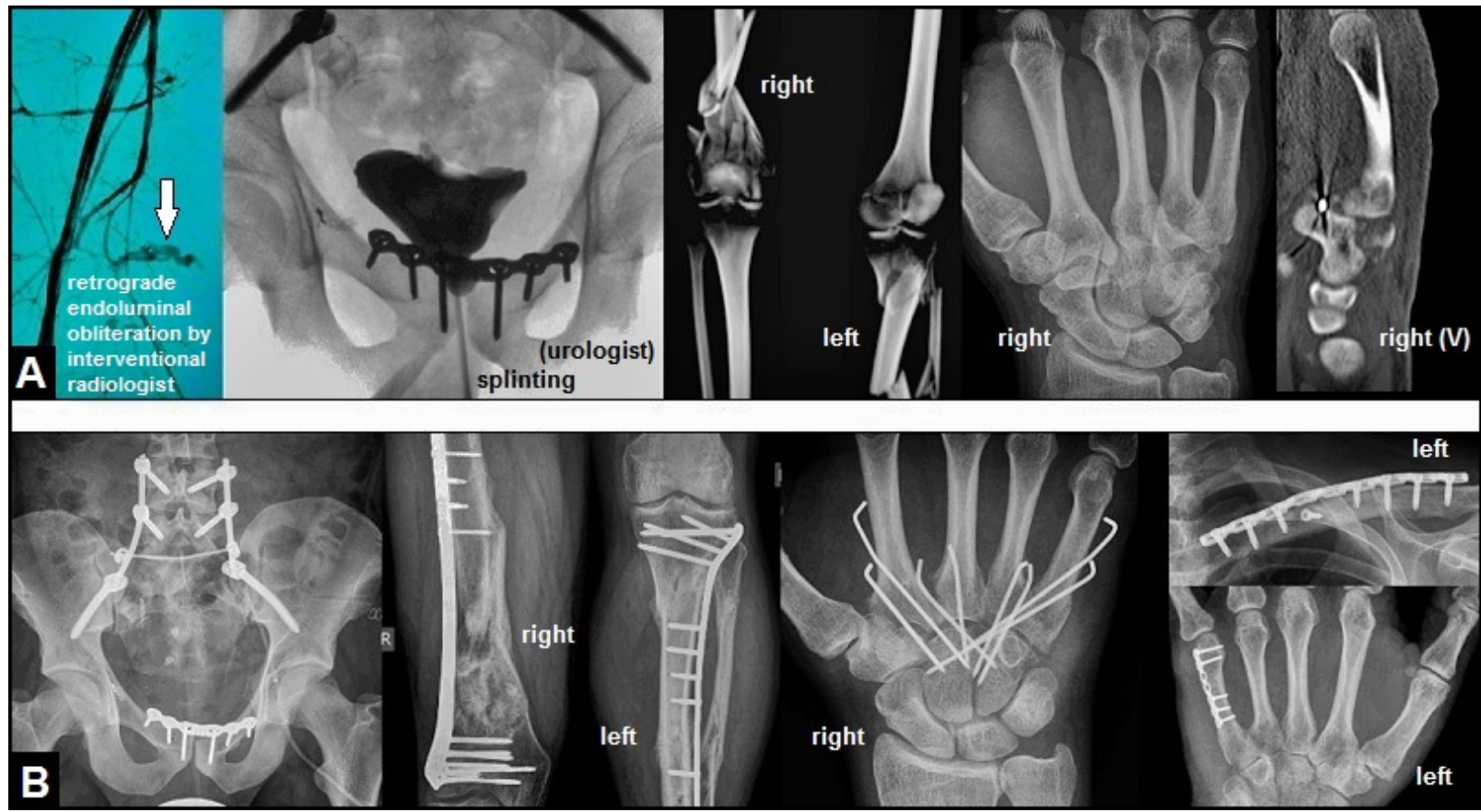

Figure 4. (Example for injury pattern in a 24-year-old critically ill polytraumatized male after an accidental fall from height): (A) Retroperitoneal bleeding due to a disruption of a branch of the right internal iliac artery (arrow), unstable fractures of the lower lumbar spine, unstable pelvic fracture with urethral rupture, highly comminuted fractures of the lower extremities, fracture-dislocation injuries of the right carpometacarpal joints II-V, left clavicle fracture, fracture of the left metacarpal bone $\mathrm{V}$ (injury severity score 41 , systolic blood pressure $40 \mathrm{mmHg}$, haemoglobin level 1,2 mmol/), initially treated by CLEFs. (B) This young patient has survived and could be recovered interdisciplinary by ORIFs (lumbar spine by the spine surgeon).
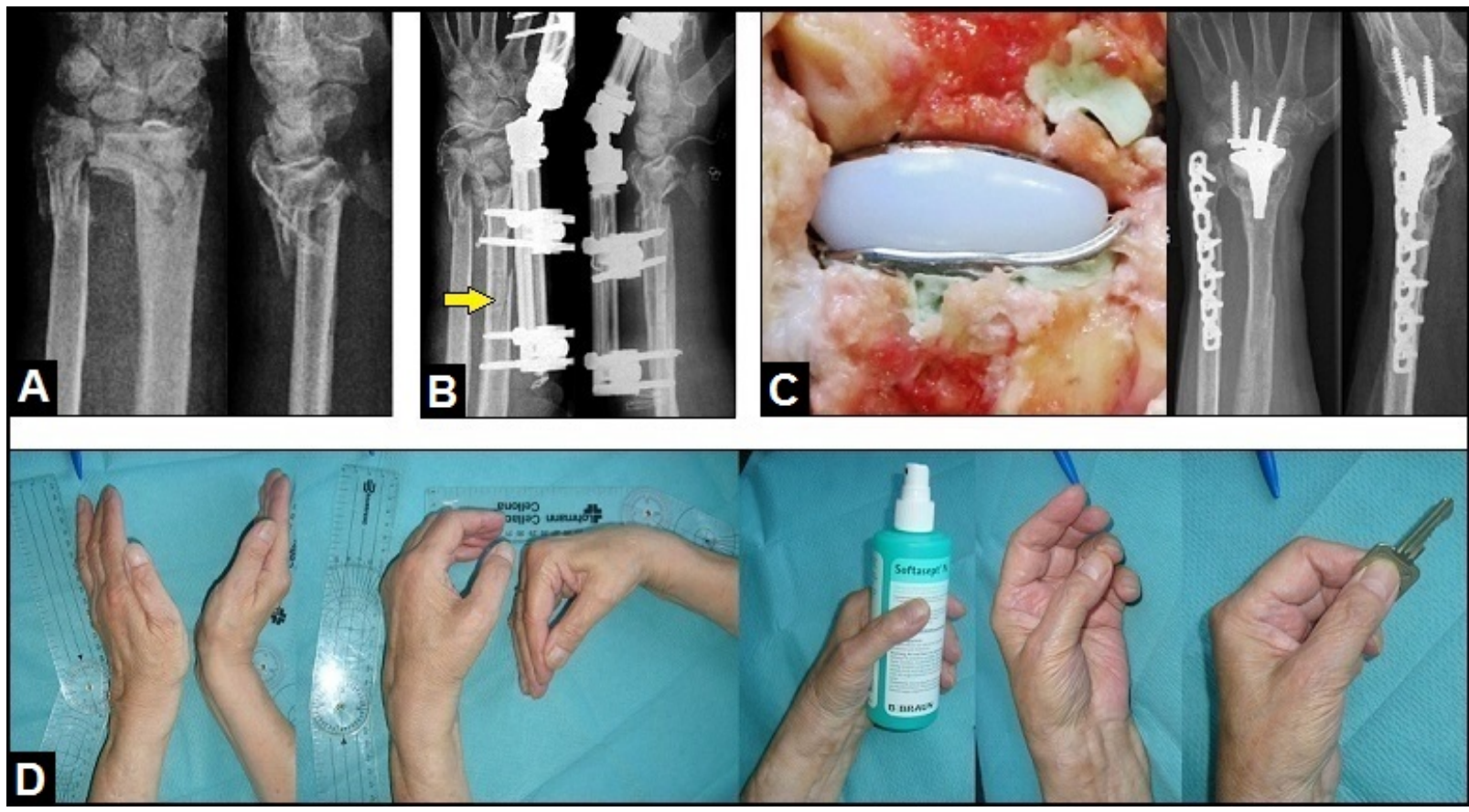

Figure 5. (Example for highly comminuted left distal forearm fracture associated with severe closed soft tissue injury after an accidental fall in a 71-year-old female with poor osteoporotic bone stock): (A) The radiograph demonstrating highly comminuted distal forearm fracture. (B) Same patient, primarily treated by CREF, note there was an additional iatrogenic fracture of the radial shaft intraoperatively due to the poor osteoporotic bone stock (arrow). (C) Same patient, definitive ORIF of distal ulna and early motion-preserving partially cemented total wrist replacement using the resurfacing RE-MOTION ${ }^{\mathrm{TM}}$ total wrist (Stryker Corporation, Kalamazoo, Michigan/USA) after consolidation of closed soft tissue injury. (D) Same patient, excellent functional outcome 2 years after total wrist replacement.

can lessen the duration of wound healing, promotes better capillary circulation, and decreases the bacterial load [21]. It must be noted that a closed soft tissue injury after fall or jump from height can be associated in $33 \%$ of cases with a subcutaneous décollement as the result of applied tangential or orthogonal forces onto a small, solid and flat surface, and it is statistically more common in accidental falls than in suicidal jumps or in unclarified causes of fall [8]. The key stone in surgical management is the second stage that includes coverage of soft tissue defects [7,22-28]. The use of the DPNFCSAF is one option for coverage of wounds around the ankle and heel, but not free of any 
Schmidt I (2017) Necessity of secondary Syme amputation of the foot after severely destroyed hindfoot injury due to suicidal jump from height in a psychiatric patient: Case presentation and brief review of literature

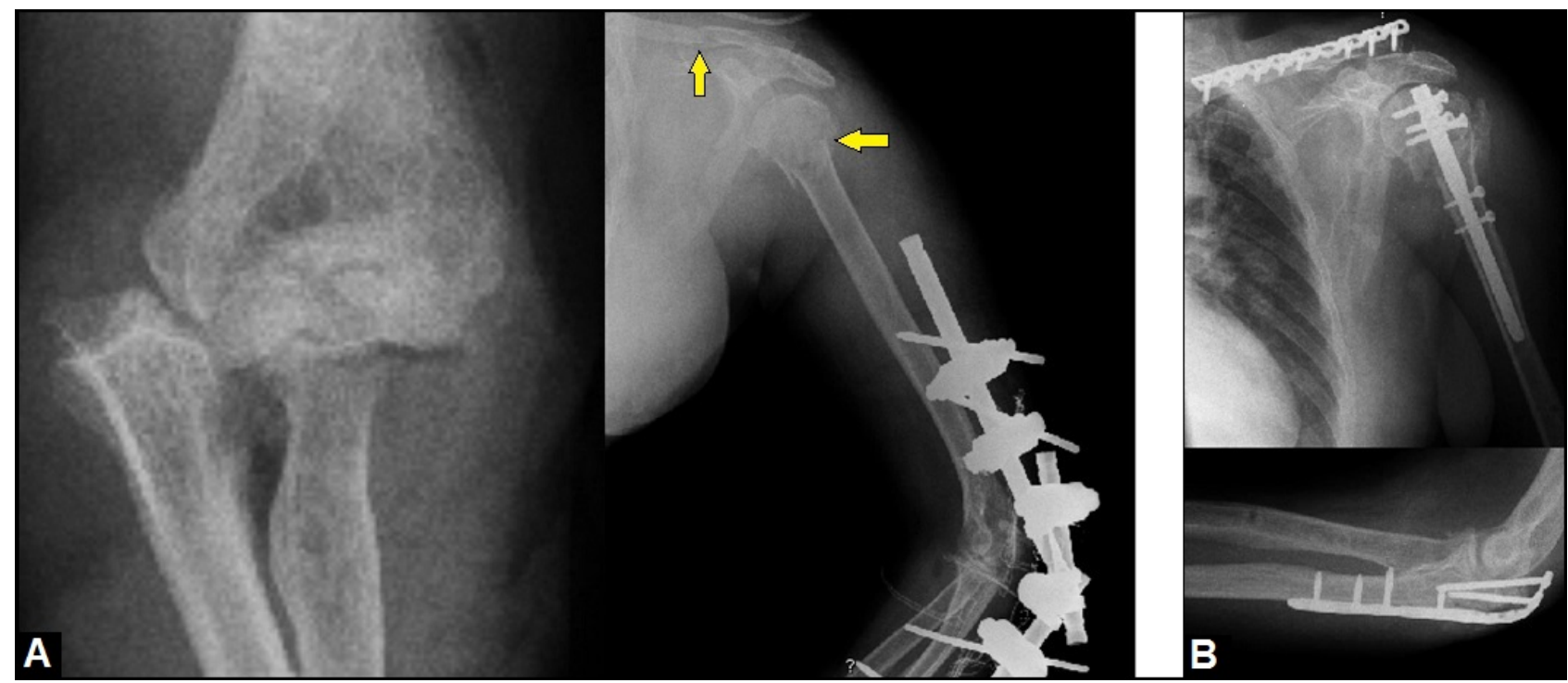

Figure 6. (Example for fracture-dislocation injury of the left elbow associated with severe closed soft tissue injury after an accidental fall from height in a 42-year-old male): (A) Initial findings, primarily treated by CREF, note the additional fractures of the clavicle and humeral head (arrows). (B) Same patient, ORIFs were performed after consolidation of soft tissue injury.
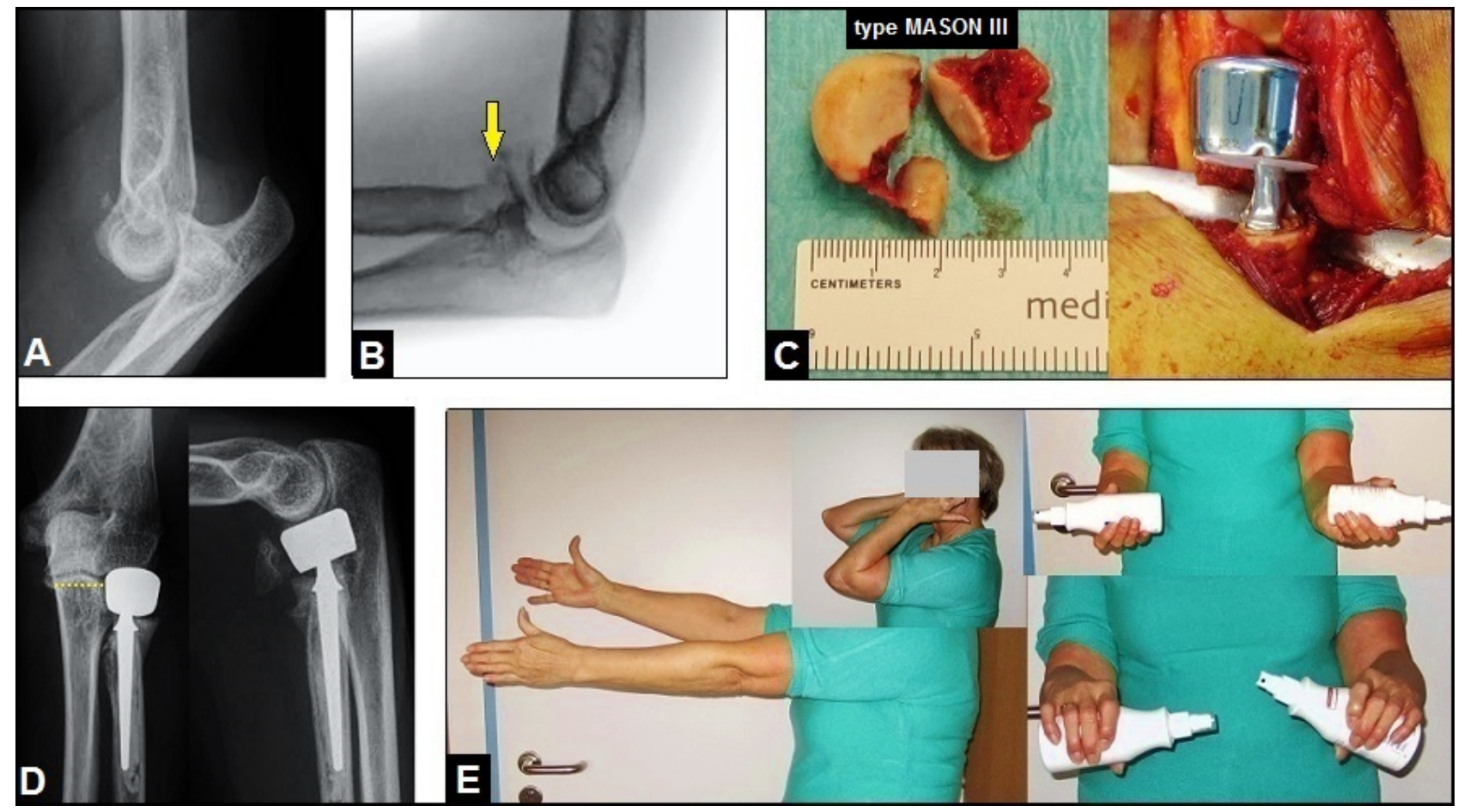

Figure 7. (Example for highly comminuted fracture-dislocation injury of the left elbow associated with severe closed soft tissue injury after an accidental fall from height in a 62 -year-old female): (A) Initial finding, terrible triad injury. (B) Same patient, primarily treated by CREF, note the highly comminuted intra-articular radial head fracture type MASON III (yellow arrow) (C) Same patient, insertion of a cemented bipolar radial head prosthesis (TORNIERC), Montbonnot Saint Martin/France) after consolidation of closed soft tissue injury. (D) Same patient, correct alignment of implant without any signs of overstuffing (yellow pointed line). (E) Same patient, excellent functional outcome 6 months after injury.

complications mostly based on venous congestion [29-32]. One option to avoid venous congestion, such as in our presented case, is that the pedicle of flap is primarily covered by a synthetic skin substitute at its pivot point extending up distally to the flap, and secondarily covered by split-thickness skin grafts $[32,33]$. The third stage includes the motion-preserving $\mathrm{O}(\mathrm{C}) \mathrm{RIF}$ (Figures $4 \mathrm{~B}, 6 \mathrm{~B}$ and $8 \mathrm{C}-\mathrm{E}$ ) with or without the necessity for reconstruction of bony defects utilizing bone grafts $[23,24,34-36]$. When the injury is finally resulted in an irreparable damage of articular surface (i.e. posttraumatic osteoarthritis), the salvage options (i.e. "fourth stage of management") are joint replacement, joint arthrodesis with or without required correction of misalignment (Figures 9A-C), or amputation when limb salvage procedures become not possible [19,28,36-45]. A reasonable option to $\mathrm{O}(\mathrm{C}) \mathrm{RIF}$ for highly comminuted fractures can be primary motion preserving total or partial joint replacement at the lower and upper extremities for surgeons who are familiar with its use (Figures 5C-D and 7C-E) [46-53]. Bone lengthening (i.e. callus distraction), nerve and tendon repair, treatment of secondary soft tissue complications 


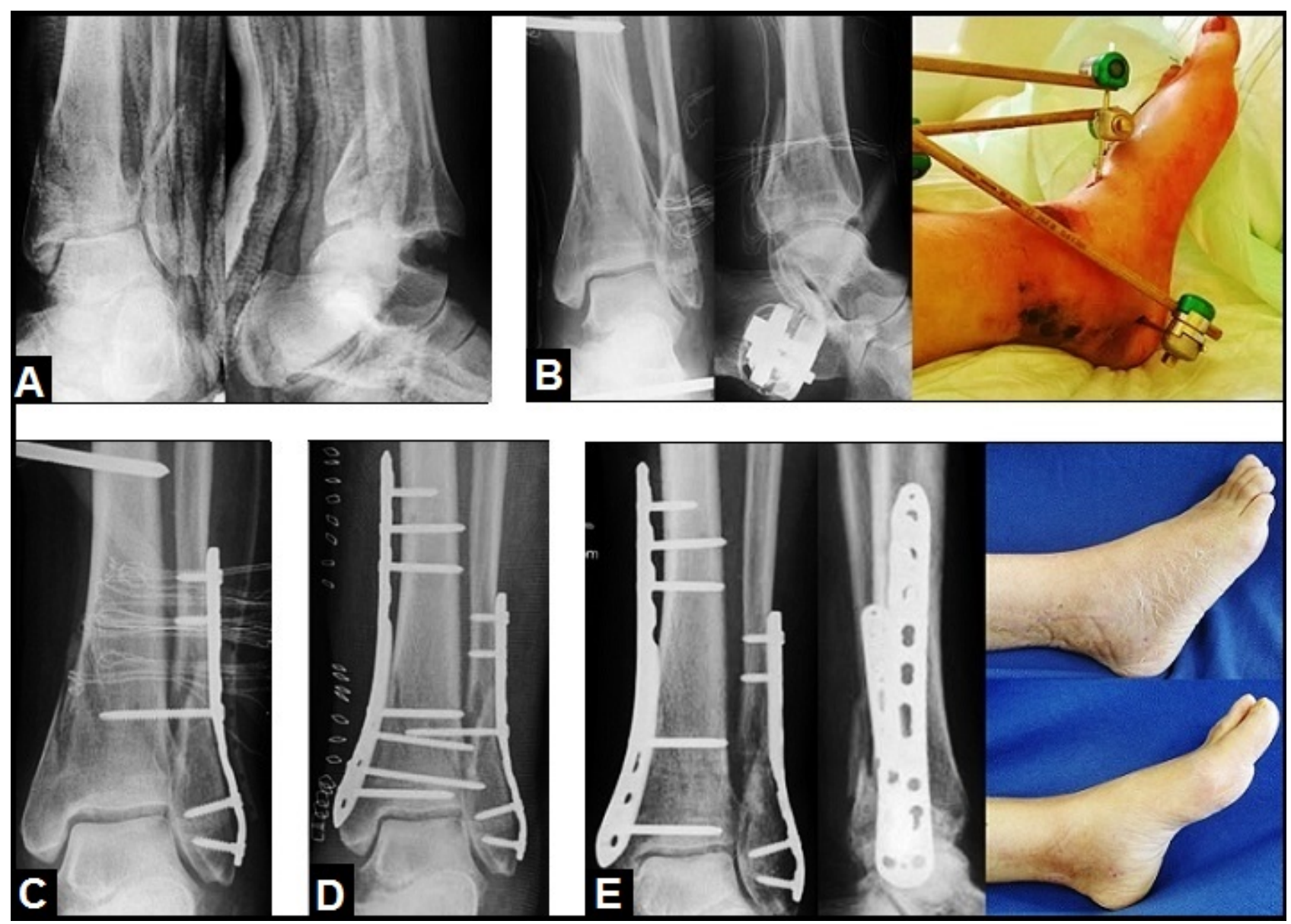

Figure 8. (Example for three-stage management of a left ankle fracture-dislocation injury accompanied with a marked closed soft tissue injury in a 57-year-old female): (A) Radiographs of the ankle in a plaster splint at first presentation in our hospital 2 days after injury, there was a re-dislocation in ankle joint, the patient was primarily treated by closed reduction and immobilization by the plaster splint in a foreign country. (B) CREF was performed in our hospital, note the superficial soft tissue necroses ventral and medial-plantar of the ankle. (C) Minimally-invasive ORIF of distal fibula in the presence of external fixation. (D) Removal of external fixation and minimally-invasive ORIF of distal tibia after consolidation of closed soft tissue injury which was treated non-operatively, an anatomically correct alignment of the ankle including its articular surface could achieved. (E) The patient could be recovered completely 3 months after injury.

with or without exposure of osteosynthesis plates or endoprostheses with or without infection, treatment of other trauma- or surgeryrelated complications such as malignancy or failed ORIF, and silicone epitheses can become necessary to restore or improve statics, function, and aesthetics in the further course (Figures 10A-B) [10,37,54-60]. It must be noted that surgical amputation after complication of minor trauma or surgery regardless any problems with the wound healing can be the "last exit" for functional recovery of patients with psychiatric disorders as well [61].

In the literature, it is still controversial in decision making whether we should perform a primary surgical amputation or limb salvage procedures in non-critically ill polytraumatized patients with severely destroyed hindfoot injuries. Patients with limb salvage procedures reported less favorable outcomes than patients sustaining primary surgical amputation related to mobility, activity, social interaction, emotional behavior, pain with walking, returning to work, and the number of required rehospitalizations for secondary surgical procedures [9,62-65]. On the other hand, limb salvage procedures may have result in good outcomes in females younger than 35 years with a high level college education, and ORIF seems to have better outcomes than CLEF $[7,66]$. When posttraumatic or postoperative osteomyelitis occurs that can also be based on initial treatment failures such as delayed wound closure in $28,8 \%$ of cases, secondary amputation at the lower extremity is not always avoidable $[8,26,66-68]$. Limb salvage in case of a posttraumatic osteomyelitis at the distal tibia metaphysis, such as in our presented case, is a challenging therapeutic problem. Successful treatment can be associated with a large number up to 18 required surgical procedures over a period of 3 months, and followed by a further duration of 6 months for ambulatory rehabilitation [31]. Essential prerequisite for doing this is the compliance of patients that was not given in our presented case.

James Syme (1799-1870), one of the last and greatest pre-Listerian surgeons from Scotland, first performed his amputation technique in 1842 in a 16-year-old boy who suffered from caries of the tarsal bones, almost certainly tuberculosis, after his own experiences with the Chopart's disarticulation over a period of 13 years in Edinburgh, and he has described his new technique as follows in the original: "... As the disease had extended beyond the limits of Chopart's amputation it would have been necessary in accordance with ordinary practice to remove the leg below the knee, but as the ankle joint seemed sound I resolved to perform a disarticulation there. With this in view, I cut across the instep in a curved direction with the convexity towards the toes, and then across the sole of the foot so that the incisions were nearly opposite one another. The flaps thus formed were next separated from their subjacent connexions which was easily effected except at the heel 
Schmidt I (2017) Necessity of secondary Syme amputation of the foot after severely destroyed hindfoot injury due to suicidal jump from height in a psychiatric patient: Case presentation and brief review of literature

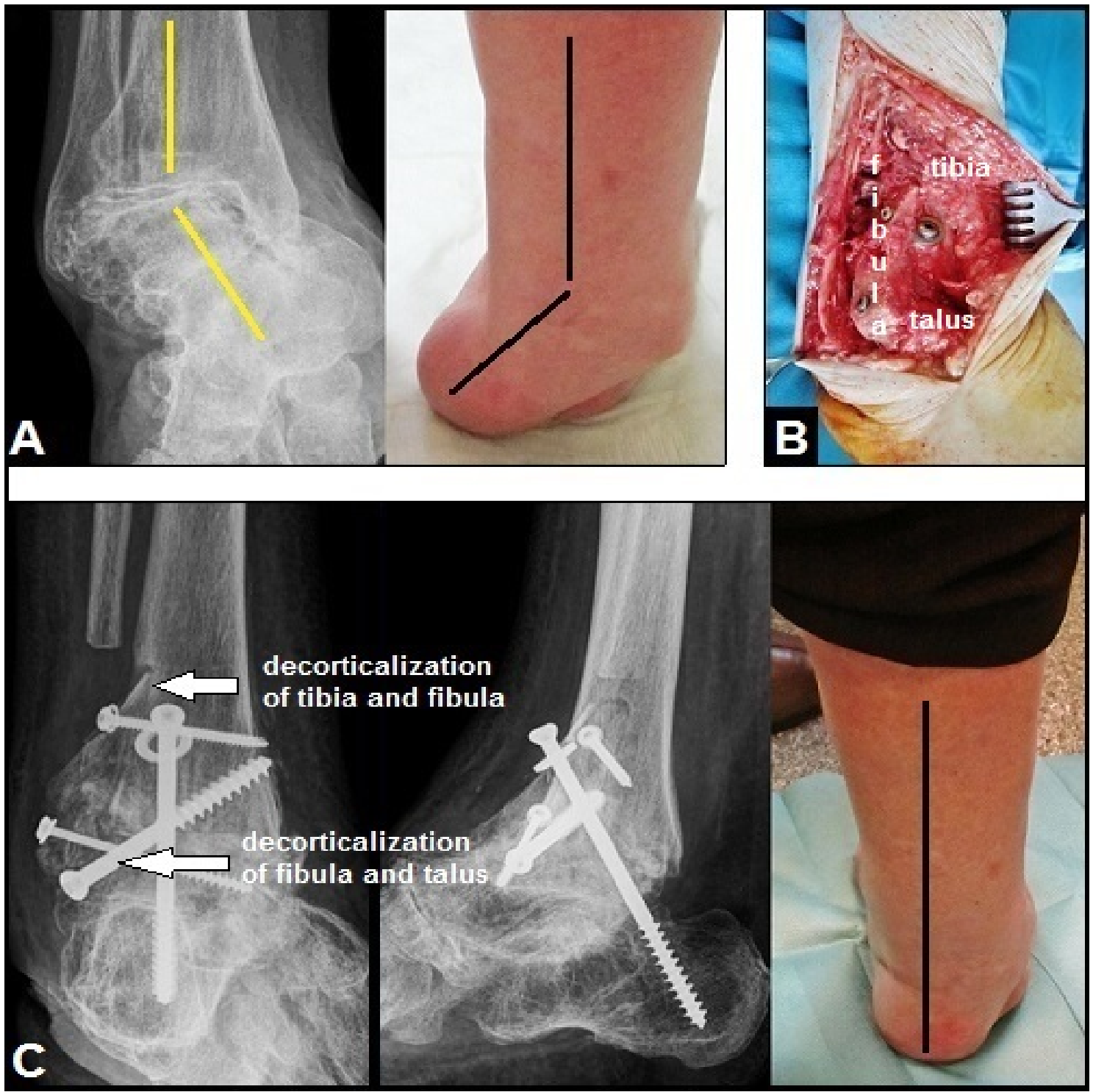

Figure 9. (Example for required right ankle arthrodesis due to posttraumatic OA in a 68-year-old female): (A) Preoperative, advanced stage of posttraumatic OA with severe longstanding varus deformity (lines). (B) Intraoperative, a corrective arthrodesis utilizing the fibula-to-tibia and talus technique (Horwitz, 1942 / Marquardt, 1951) with titanium screws was performed. (C) One year postoperatively, ankle arthrodesis is unioned accompanied with sufficient correction of varus deformity (line).

where the firmness of texture caused a little difficulty. The disarticulation being readily completed, the malleolar projections were removed by means of cutting pliers." $[69,70]$. Interestingly, archaeological findings at the northern coastal of Peru suggest that surgical disarticulations in ankle joint similar to Syme's technique could have been performed quite substantially earlier during the Moche culture in the ancient pre-European period (AD 100-750) approximately 1.500 years before Syme's first description, and a ceramic vessel of the Moche culture in the American Museum of Natural History (New York) showing that these patients could already have used orthotic devices for their stumps [71]. The aim of this procedure is that there is a bulky full-weight bearing stump on a broad-based bony support obtaining the plantar heel's flap sensibility which make it possible to stand upright on the stump without an orthotic device for example in a shower or a swimming pool $[72,73]$. Syme advocated that the calcaneus should be dissected subperiostally from the heel flap, it leaves the heel flap lined with the periost which more readily adheres to the cut surface of the tibia, and so, a posterior displacement of flap can be avoided [74]. Essential prerequisite for success of this procedure is the careful dissection of the posterior neurovascular bundle behind the medial malleolus before performing the transmetaphysal single cut that involves both malleoli, and the success rate also depends on the degree of skill and attention on the part of the surgeon [75]. If the plantar heel flap does not show sufficient blood supply after release of tourniquet, the twostage Wagner's procedure can be helpful that includes a secondary stump's closure with the flap [76]. After wound healing the heel flap should be strapped to the lower leg to ensure its position, however, its posterior displacement is one of the most common problem [72,74,77]. The resultant leg shortening up to $8 \mathrm{~cm}$ must be compensated with a specific orthotic device (i.e. Syme prosthesis) which make it possible to make the bulky stump less apparent [78,79]. Weaver et al. reported on 35 patients with a primary wound healing in $86 \%$ of cases, and $97 \%$ of them could be successfully rehabilitated [80]. For high-risk patients (diabetes, peripheral arterial disease, infection) in whom major amputation had been recommended, a wound healing could be achieved in $50 \%$ of cases, and $26 \%$ of cases were functioning well in a 


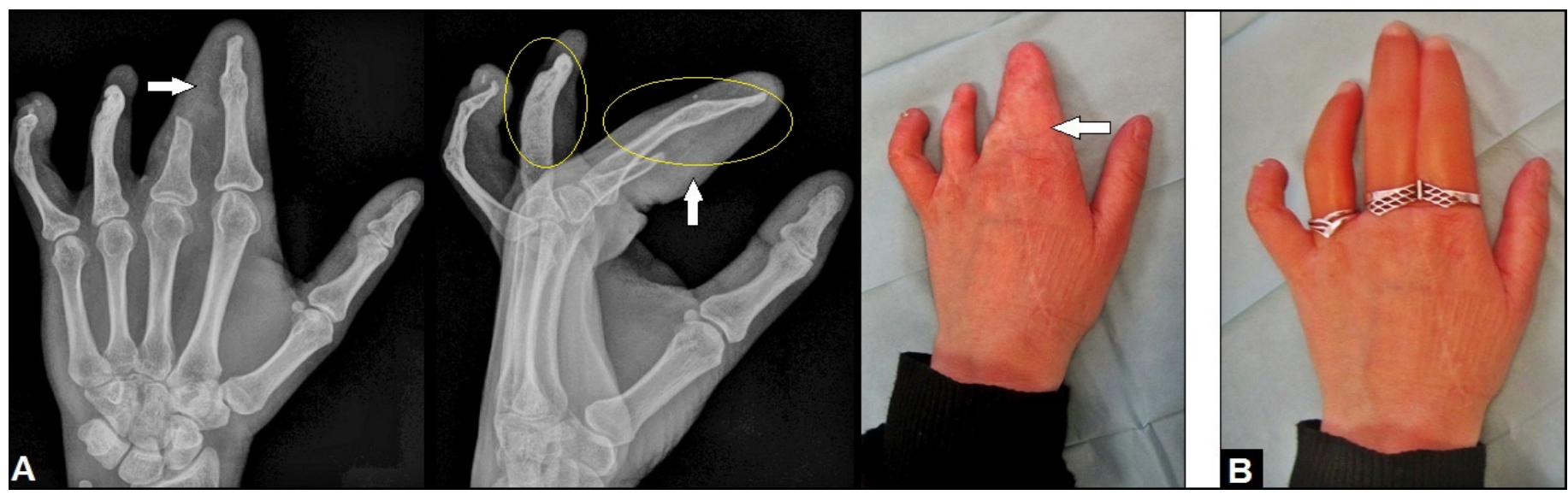

Figure 10. (Example for reconstruction of statics, function, and cosmetics after a severe occupational crush injury of the left hand in a 26 -year-old female, 20-year follow-up): (A) The stumps of the 2nd and 4th proximal phalanges were lengthened (yellow ovals) with the use of the Jena-MINIFIX [14,17,18] after wrapping the stumps of the 2nd and 3rd proximal phalanges with the use of a distally pedicled radial artery flap (white arrows). (B) Aesthetic outcome had significantly improved for the patient with individually customized silicone epitheses for the 2nd, 3rd, and 4th finger (ottobock., Duderstadt/Germany).

Syme prosthesis, respectively [81]. It is noted that the failure rate of Syme's amputation (i.e. revision to a more proximal level) is with a relative portion of $41 \%$ in patients with dysvascular lesions significantly higher than in patients with traumatic injuries with $29 \%$, and so, this technique is not always recommended for patients with peripheral arterial disease and/or diabetes [77]. The essential key point for success is the clinical assessment of ankle pulses before surgery. Francis et al. found that in $85 \%$ of patients the Syme amputation was successful when the posterior tibial artery pulse was palpable in comparison to $25 \%$ of patients only in whom the pulses were not palpable [82]. However, recent long-term data derive the opinion that patients who underwent Syme's amputation appear to fare better than similar patients with transtibial amputation. These data also refute the notion of high complication rates and difficulties with prosthetic fitting. These patients required less rehabilitation and achieved improved levels of functional independence as demonstrated by favorable functional, mobility, and bothersome indices [83].

\section{Conclusion}

Despite all modern aspects in trauma and reconstructive surgery it is to be considered by the authors that the Syme amputation of the left severe posttraumatic flat foot accompanied with pronounced posttraumatic osteomyelitis of the hindfoot involving the distal tibia metaphysis was the only method of choice for early recovery (i.e. end-bearing mobilization) of our patient with psychiatric disorder accompanied with suicidal tendency (i.e. non-compliance). Furthermore, it seems to be doubtful whether a reconstruction (i.e. third stage of management) of her also right severe posttraumatic flat foot based on pronounced calcaneal non-union becomes possible with our critical patient's situation, and all surgeons should be aware about their objectives as well as their limitations, and the wishes and claims on the part of the patients in such a specific situation $[84,85]$.

\section{Conflict of interests}

The authors declare that they have none conflict of interests concerning this article.

\section{Acknowledgements}

The corresponding author would like to thank Univ. Prof. em. Dr. med. habil. Eberhard Markgraf (Jena/Germany, President of the
German Society for Traumatology (DGU) in 1996, Member of the Senate of the DGU, Honouring with the Carl Thiem Commemorative Medallion of the DGU in 2002, Honourary Member of the DGU since 2007, Trustee Member of the AO Foundation) and Dr. med. Reinhard Friedel (University Hospital Jena/Germany, Head of the Department for Hand and Replantation Surgery) for their complex and excellent teaching in Trauma, Orthopaedic, Hand, Replantation, and Plastic Surgery during his training at the University Hospital Jena between 1990-1999.

\section{References}

1. Abel SM, Ramsey S (2013) Patterns of skeletal trauma in suicidal bridge jumpers: a retrospective study from the southeastern United States. Forensic Sci Int 231: 399 e1-5. [Crossref]

2. Moeller K, Letsch R (1997) Injuries in suicidal falls from heights: A case study on 48 patients. Unfallchirurgie (Europ J of Trauma) 23: 137-143. [Crossref]

3. Pollak S, Missliwetz J (1979) Suicides in hospitals of Vienna (author's transl). Z Rechtsmed 83: 233-244. [Crossref]

4. Ruchholtz S, Nast-Kolb D, Waydhas C, Schweiberer L (1996) The injury pattern in polytrauma. Value of information regarding accident process in clinical acute management. Unfallchirurg 99: 633-641.

5. Probst C, Richter M, Lefering R, Frink M, Gaulke R, et al. (2010) Incidence and significance of injuries to the foot and ankle in polytrauma patients--an analysis of the Trauma Registry of DGU. Injury 41: 210-215. [Crossref]

6. Richter M, Thermann H, Huefner T, Schmidt U, Goesling T, et al. (2004) Chopart joint fracture-dislocation: initial open reduction provides better outcome than closed reduction. Foot Ankle Int 25: 340-348. [Crossref]

7. Gustilo RB, Anderson JT (1976) Prevention of infection in the treatment of one thousand and twenty-five open fractures of long bones: retrospective and prospective analyses. J Bone Joint Surg Am 58: 453-458. [Crossref]

8. Atanasijevic T, Popovic V, Mihailovic Z, Radnic B, Soldatovic I, et al. (2015) Analysis of Closed Soft Tissue Subcutaneous Injuries-"Impact Décollement" in Fatal Free Falls From Height-Forensic Aspect. Am J Forensic Med Pathol 36: 145-148.

9. Edelstein DA, Florescu I (2016) Crushing injuries of the foot and ankle, with complex open fractures: result of a prospective study with a 3 year follow-up. $J$ Med Life 9 . 255-258. [Crossref]

10. Friedel R, Schmidt I (1997) The treatment concept in severe hand injuries. Zentralbl Chir 122: 1016-1023. [Crossref]

11. Rammelt S, Biewener A, Grass R, Zwipp H (2005) Foot injuries in the polytraumatized patient. Unfallchirurg 108: 858-865. [Crossref]

12. Markgraf E, Schmidt I, Friedel R, Dönicke T (1996) The pathophysiology of wound healing processes - Overview. OP-JOURNAL (Thieme, Stuttgart - New York) 12: 4-9. 
Schmidt I (2017) Necessity of secondary Syme amputation of the foot after severely destroyed hindfoot injury due to suicidal jump from height in a psychiatric patient: Case presentation and brief review of literature

13. Schmidt I, Markgraf E, Friedel R (1997) The hand injury in polytrauma. OP-JOURNAL (Thieme, Stuttgart - New York) 13: 146-150.

14. Markgraf E, Friedel R, Dorow C, Schmidt I (1997) Traumatology of the hand. In: Oestern HJ and Probst J (eds.) Unfallchirurgie in Deutschland (Springer, Heidelberg) Chapter 26: 454-472

15. Schmidt I (2017) The gastrocnemius muscle flap for coverage of soft tissue defect of the proximal third of lower leg. Int J Case Rep Images 8: 168-170.

16. Hernigou P (2017) History of external fixation for treatment of fractures. Int Orthop 41: 845-853. [Crossref]

17. Schmidt I, Markgraf E, Friedel R, Biedermann F, Dönicke T (1995) Indications for a new joint-bridging miniature external fixator in primary and secondary managment of complex hand injuries. Zentralbl Chir 120: 945-951.

18. Friedel R, Schmidt I, Markgraf E (2000) Indication and use of various external fixation systems at the injured hand. Osteosynthese International, Gerhard Küntscher Society, Frankfurt/M. 1999 Johann Ambrosius Barth, Leipzig 8 Suppl 1: S102-S103.

19. Schmidt I (2017) Posttraumatic ulnar carpal translocation type I accompanied with disruption of the lunotriquetral ligament caused by a severe radiocarpal fracturedislocation injury type II accompanied with complete luxation of the distal radioulnar joint. What are the salvage options with its special features in indication when patients develop posttraumatic painful wrist joint osteoarthritis? Trauma Emerg Care 2: doi: 10.15761/TEC.1000138.

20. Schmidt AH, Bosse MJ, Frey KP, O’Toole RV, Stinner DJ, Scharfstein DO, Zipunnikov V, MacKenzie EJ; METRC (2017) Predicting Acute Compartment Syndrome (PACS): The Role of Continuous Monitoring. J Orthop Trauma 31 Suppl 1: S40-S47. [Crossref]

21. Plikaitis CM, Molnar JA (2006) Subatmospheric pressure wound therapy and the vacuum-assisted closure device: basic science and current clinical successes. Expert Rev Med Devices 3: 175-184. [Crossref]

22. Tscherne H, Oestern HJ (1982) A new classification of soft-tissue damage in open and closed fractures (author's transl). Unfallheilkunde 85: 111-115. [Crossref]

23. Schmidt I (1996) Strategy and management of complex injuries of the hand. Unfallmedizinische Tagung des Landesverbandes Hessen-Mittelrhein und Thüringen der gewerblichen Berufsgenossenschaften (9./10. November in Mainz) 96: 208-221.

24. Zwipp H, Rammelt S, Barthel S (2005) Fracture of the calcaneus. Unfallchirurg 108: 737-747. [Crossref]

25. Rammelt S, Zwipp H (2004) Calcaneus fractures: facts, controversies and recent developments. Injury 35: 443-461. [Crossref]

26. Barshes NR, Mindru C, Ashong C, Rodriguez-Barradas M, Trautner BW (2016) Treatment Failure and Leg Amputation Among Patients With Foot Osteomyelitis. Int $J$ Low Extrem Wounds 15: 303-312.

27. Dorow C, Markgraf E (1997) Therapy of soft tissue injuries--biological strategies. Zentralbl Chir 122: 962-969.

28. Bach O, Hope MJ, Chaheka CV, Dzimbiri KM (2004) Disability can be avoided after open fractures in Africa-results from Malawi. Injury 35: 846-851. [Crossref]

29. Schmidt I, Schmieder A, Kilian O (2012) The simultaneous distally based sural flap. A therapeutic option for coverage of both heels. Unfallchirurg 115: 267-272.

30. Park JS, Roh SG, Lee NH, Yang KM (2013) Versatility of the distally-based sura artery fasciocutaneous flap on the lower leg and foot in patients with chronic disease. Arch Plast Surg 40: 220-225. [Crossref]

31. Schmidt I (2016) Long-term outcome in a patient with severe postoperative osteomyelitis of the critical distal third of lower leg. Int $J$ Case Rep Images 7: 680-682.

32. Schmidt I (2017) The distally pedicled peroneus brevis muscle and fasciocutaneous sural artery flap for reconstruction of the distal third of lower leg. Int J Case Rep Images 8: $17-21$.

33. Schmidt I (2017) The proximally and distally pedicled hemisoleus muscle flap for coverage of soft tissue defects in the middle third of lower leg. Trauma Emerg Care 2: doi: $10.15761 /$ TEC. 1000151 .

34. Friedel R, Dorow C, Schmidt I, Fährmann M (1995) [Principles of osteosynthesis of the hand]. Zentralbl Chir 120: 934-939. [Crossref]

35. Schmidt I (1997) Fractures and dislocations of the hand skeleton. Ärztebl Thür 8: 566-569.

36. Schmidt I (2017) A 20-year follow-up after replantation of the right midfoot in an eight-year-old child. In J Case Rep Images 8: 293-295.
37. Schmidt I (2017) A Complicated Course of a Coronal Shear Fracture Type IV of the Distal Part of Humerus Resulting in Resurfacing Radiocapitellar Joint Replacement Open Orthop J 11: 248-254.

38. Schmidt I (2017) Does Total Wrist Arthroplasty for Treatment of Posttraumatic Wris Joint Osteoarthritis in Young Patients Always Lead to Restriction of High-demand Activities of Daily Living? Case Report and Brief Review of Recent Literature. Open Orthop J 11: 439-446.

39. Schmidt I (2017) The Maestro ${ }^{\mathrm{TM}}$ Wrist Reconstructive System for treatment of posttraumatic wrist joint osteoarthritis after a devasting course of a distal radius fracture: Case presentation and technical note to the implant. Trauma Emerg Care 2: doi: 10.15761/TEC.1000124.

40. Schmidt I (2017) RE-MOTION ${ }^{\mathrm{TM}}$ total wrist arthroplasty for treatment of advanced stage of scaphoid non-union advanced collapse. Does excision of the entire scaphoid bone prevent impingement at terminal range of radial deviation? Trauma Emerg Care 2: doi: 10.15761/TEC.1000127.

41. Rammelt S, Zwipp H (2013) Corrective arthrodeses and osteotomies for post-traumatic hindfoot malalignment: indications, techniques, results. Int Orthop 37: 1707-1717.

42. Richter M, Zech S2 (2016) Tibiotalocalcaneal arthrodesis with a triple-bend intramedullary nail (A3)-2-year follow-up in 60 patients. Foot Ankle Surg 22: 131-138. [Crossref]

43. Brodsky JW, Kane JM, Taniguchi A, Coleman S, Daoud Y. (2017) Role of Total Ankle Arthroplasty in Stiff Ankles. Foot Ankle Int. doi: 10.1177/1071100717718130. [Epub ahead of print] [Crossref]

44. Schmidt I (2014) Primary combined replacements for treatment of distal radius physea arrest. J Wrist Surg 3: 203-205. [Crossref]

45. Reigstad O, Holm-Glad T, Bolstad B, Grimsgaard C, Thorkildsen R, et al. (2017) Five- to 10-Year Prospective Follow-Up of Wrist Arthroplasty in 56 Nonrheumatoid Patients. J Hand Surg Am. 10.1016/j.jhsa.2017.06.097. [Epub ahead of print] [Crossref]

46. Brett K, Lapner P (2017) Shoulder Arthroplasty for Acute Proximal Humerus Fracture A Review. Open Orthop J 11: BSP-TOORTHJ-2017-HT10-4.

47. Sørensen BW, Brorson S, Olsen BS (2014) Primary total elbow arthroplasty in complex fractures of the distal humerus. World J Orthop 5: 368-372. [Crossref]

48. Winter M, Chuinard C, Cikes A, Pelegri C, Bronsard N, et al. (2009) Surgical management of elbow dislocation associated with non-reparable fractures of the radial head. Chir Main 28: 158-167.

49. Yan M, Ni J, Song D, Ding M, Liu T, et al. (2015) Radial head replacement or repair for the terrible triad of the elbow: which procedure is better? ANZ J Surg 85: 644-648. [Crossref]

50. Malviya A, Reed MR, Partington PF (2011) Acute primary total knee arthroplasty for peri-articular knee fractures in patients over 65 years of age. Injury 42: 1368-1371. [Crossref]

51. Schmidt I (2015) Can Total Wrist Arthroplasty Be an Option for Treatment of Highly Comminuted Distal Radius Fracture in Selected Patients? Preliminary Experience with Two Cases. Case Rep Orthop doi: 10.1155/2015/380935. Epub 2015 Sep 29.

52. Schmidt I (2017) Distal radioulnar synostosis after primary combined replacements for treatment of highly comminuted distal radius fracture in an elderly patient. $J$ Hand Surg Eur Vol 42: 97-98.

53. Barrera-Ochoa S, Mendez-Sanchez G, Mir-Bullo X (2017) Primary trapeziometacarpal prosthesis for complicated fracture of the base of the thumb metacarpal. J Hand Surg Eur Vol doi: 10.1177/1753193417719371. [Epub ahead of print] [Crossref]

54. Schmidt I (2017) Irreparable Radial Nerve Palsy Due to Delayed Diagnostic Management of a Giant Lipoma at the Proximal Forearm Resulting in a Triple Tendon Transfer Procedure: Case report and Brief Review of Literature. Open Orthop $J 11$ : 794-803.

55. Schmidt I (2016) The proximally based hemisoleus muscle flap for coverage of large soft tissue defect of the middle third of lower leg. Int J Case Rep Images 7: 683-684.

56. Schmidt I (2016) A large proximally pedicled random skin transposition flap for reconstruction of a critically compromised lower extremity. Int J Case Rep Images 7: 685-686.

57. Schmidt I (2016) The distally pedicled peroneus brevis muscle flap for treatment of an arthrocutaneous fistula after ankle arthroscopy: case report. JSM Clin Case Rep 4: 1115.

58. Schmidt I (2017) The role of gastrocnemius muscle flap for reconstruction of large soft tissue defects after infected total knee arthroplasty. Int $J$ Case Rep Images 8: 7-10. 
Schmidt I (2017) Necessity of secondary Syme amputation of the foot after severely destroyed hindfoot injury due to suicidal jump from height in a psychiatric patient: Case presentation and brief review of literature

59. Schmidt I, Friedel R, Schmitz H, Marx F, Markgraf E (2000) The "Marjolin's ulcer": a malignant and rarely complication after burn trauma of the upper extremity - A case report. Unfallchirurg 103: 68-72. [Crossref]

60. Schmidt I (2016) An Unusual and Complicated Course of a Giant Cell Tumor of the Capitate Bone. Case Rep Orthop 2016: 3705808. [Crossref]

61. Weis T, Boeckstyns ME (2009) The clenched fist syndrome: a presentation of eight cases and an analysis of the medicolegal aspects in Denmark. J Hand Surg Eur Vol 34: 374-378. [Crossref]

62. Myerson MS, McGarvey WC, Henderson MR, Hakim J (1994) Morbidity after crush injuries to the foot. J Orthop Trauma 8: 343-349. [Crossref]

63. Sanders R, Pappas J, Mast J, Helfet D (1992) The salvage of open grade IIIB ankle and talus fractures. J Orthop Trauma 6: 201-208. [Crossref]

64. Ellington JK, Bosse MJ, Castillo RC, MacKenzie EJ; LEAP Study Group (2013) The mangled foot and ankle: results from a 2-year prospective study. J Orthop Trauma 27: 43-48. [Crossref]

65. Ferreira RC, Sakata MA, Costa MT, Frizzo GG, Santin RA (2010) Long-term results of salvage surgery in severely injured feet. Foot Ankle Int 31: 113-123. [Crossref]

66. Bosse MJ, Teague D, Reider L, Gary JL, Morshed S, et al. (2017) Outcomes After Severe Distal Tibia, Ankle, and/or Foot Trauma: Comparison of Limb Salvage Versus Transtibial Amputation (OUTLET). J Orthop Trauma 31 Suppl 1: S48-S55. [Crossref]

67. Rammelt S, Olbrich A, Zwipp H (2011) [Hindfoot amputations]. Oper Orthop Traumatol 23: 265-279. [Crossref]

68. Corti G, Mondanelli N, Losco M, Bartolini L, Fontanelli A, et al. (2009) Post-traumatic infection of the lower limb caused by rare Enterobacteriaceae and Mucorales in a young healthy male. Int J Infect Dis 13: e57-60. [Crossref]

69. Syme J (1843) On amputation at the ankle joint. London and Edinburgh Monthly Journal of Medical Science. 3, XXVI, Feb. 1843, 93.

70. Harris RI (1961) The history and development of Syme's amputation. Artif Limbs 6: 4-43. [Crossref]

71. Verano JW, Anderson LS, Franco R (2000) Foot Amputation by the Moche of Ancient Peru: Osteological Evidence and Archaeological Context. Int Osteoarchaeol 10: 177-188.
72. Brückner L (2007) Lower limb amputations: Lower Leg: Indications and Technique OP-JOURNAL (Thieme, Stuttgart - New York) 23: 200-209.

73. Sakkers R, van Wijk I2 (2016) Amputation and rotationplasty in children with limb deficiencies: current concepts. J Child Orthop 10: 619-626. [Crossref]

74. Harris RI (1956) Syme's amputation; the technical details essential for success. $J$ Bone Joint Surg Br 38-38B: 614-32. [Crossref]

75. Alldredge RH, Thompson TC (1946) The technique of the Syme amputation. J Bone Joint Surg Am 28: 415-426. [Crossref]

76. Wagner FW Jr (1977) Amputations of the foot and ankle. Current status. Clin Orthop Relat Res : 62-69. [Crossref]

77. McElwain JP, Hunter GA, English E (1985) Syme's amputation in adults: a long-term review. Can J Surg 28: 203-205. [Crossref]

78. Diveley RL, Kiene RH (1956) An improved prosthesis for a Syme amputation. J Bone Joint Surg Am 38-38A: 219-21. [Crossref]

79. Baumgartner R, Botta P (1995) Supramalleolare Amputation nach Syme. In: Baumgartner $\mathrm{R}$ and Botta $\mathrm{P}$ (eds.) Amputationen und Prothesenversorgungen der unteren Extremität (Enke, Stuttgart, 2nd ed.): 130-136.

80. Weaver FA, Modrall JG, Baek S, Harvey F, Siegal A, Rosental J, Yellin AE (1996) Syme amputation: results in patients with severe forefoot ischemia. Cardiovasc Surg 4: $81-86$

81. Frykberg RG1, Abraham S, Tierney E, Hall J (2007) Syme amputation for limb salvage: early experience with 26 cases. J Foot Ankle Surg 46: 93-100. [Crossref]

82. Francis H 3rd, Roberts JR, Clagett GP, Gottschalk F, Fisher DF Jr (1990) The Syme amputation: success in elderly diabetic patients with palpable ankle pulses. J Vasc Surg 12: $237-240$.

83. Finkler ES, Marchwiany DA, Schiff AP, Pinzur MS (2017) Long-term Outcomes Following Syme's Amputation. Foot Ankle Int 38: 732-735. [Crossref]

84. Banerjee R, Saltzman C, Anderson RB, Nickisch F (2011) Management of calcanea malunion. J Am Acad Orthop Surg 19: 27-36. [Crossref]

85. Janssen SJ, Teunis T, Guitton TG, Ring D, Science of Variation Group (2015) Do Surgeons Treat Their Patients Like They Would Treat Themselves? Clin Orthop Relat Res 473: 3564-3572. [Crossref]

Copyright: (C2017 Schmidt I. This is an open-access article distributed under the terms of the Creative Commons Attribution License, which permits unrestricted use, distribution, and reproduction in any medium, provided the original author and source are credited. 